\title{
Differential diagnosis of type 2 neurofibromatosis: molecular discrimination of NF2 and sporadic vestibular schwannomas
}

\author{
C L Wu, N Thakker, W Neary, G Black, R Lye, R T Ramsden, A P Read, D G R Evans
}

University

Department of

Medical Genetics and

Regional Genetics

Service, St Mary's

Hospital, Manchester

M13 OJH, UK

C L Wu

N Thakker

G Black

A P Read

D G R Evans

Department of

Otolaryngology,

Manchester Royal

Infirmary, Manchester,

UK

W Neary

R T Ramsden

Department of

Neurosurgery,

Manchester Royal

Infirmary, Manchester,

UK

R Lye

University

Department of

Ophthalmology,

Manchester Royal Eye

Hospital, Manchester,

UK

G Black

Correspondence to:

Dr Evans.

Received 22 July 1997

Revised version accepted for

publication 18 May 1998

\begin{abstract}
Patients who present with unilateral vestibular schwannomas either at a young age or with additional features of type 2 neurofibromatosis (NF2) are at risk of developing bilateral disease and transmitting a risk of neurogenic tumours to their offspring. We have identified 15 patients from a series of 537 with unilateral vestibular schwannomas who also had one or more of the following: other tumours (10/15), features of NF2 (3/15), or a family history of neurogenic tumours (5/15). No germline NF2 mutations were detected and in 7/9 cases where tumour material was available for analysis a germline mutation in the NF2 gene has been excluded. Although a possibility of gonosomal mosaicism still exists, exclusion tests for the offspring are now possible. We suggest a general strategy, based on analysis of tumour DNA, for distinguishing sporadic and familial cases of tumours caused by two hit mechanisms. Application of this strategy suggests that most instances of unilateral vestibular schwannoma which do not fulfil criteria for NF2 represent chance occurrences. $(\Im$ Med Genet 1998;35:973-977)
\end{abstract}

Keywords: neurofibromatosis type 2; vestibular schwannoma; somatic mosaicism; mutation

The majority of patients presenting with vestibular schwannomas (VS) have noninherited tumours that carry no further implications for the patient or family. Some, however, have type 2 neurofibromatosis (NF2, MIM 101000), an autosomal dominant inherited condition characterised by the development of bilateral VS, schwannomas of other cranial, spinal, and cutaneous nerves, and cranial and spinal meningiomas. ${ }^{1-3}$ Diagnosis of NF2 has profound implications both for the patient and his relatives. Usually the distinction is readily made between sporadic unilateral VS and familial NF2 with bilateral VS and other signs. However, some $10-20 \%$ of NF2 cases present initially with a unilateral VS..$^{2-4}$ When a patient with unilateral VS has a relative with unilateral VS (but not classical NF2), or has one or a few other features of NF2 without a family history, the differential diagnosis can be difficult. In these cases comparative analysis of DNA from the tumour and from the patient's blood may allow a correct diagnosis.
Vestibular schwannomas arise by a classical two hit mechanism ${ }^{5}$ from cells that have functionally or physically lost both copies of the NF2 gene. In sporadic VS both losses occur by somatic mutations in a genetically normal subject, while patients with NF2 inherit one mutation, which is present in every cell of their body. The picture is complicated by the frequent occurrence of genetic mosaicism, in which one mutation occurs early in embryonic development in a previously normal person ${ }^{6}$; such people have no family history of NF2 but are at risk of passing the mutation on to their children if it is present in the germline.

The NF2 gene was mapped to $22 \mathrm{q} 12$ in $1988^{7}$ and isolated in $1993^{89}$ and several reports have documented germline mutations in large series of affected cases. ${ }^{10-14}$ Unfortunately, standard mutation detection techniques such as single strand conformational polymorphisms (SSCP) or denaturing gradient gel electrophoresis (DGGE) do not detect mutations in every classically affected patient, so that failure to detect a mutation in DNA from the patient's blood cannot be used as a means of excluding NF2. We have previously reported a series of patients with unilateral VS and other features suggestive of NF2. ${ }^{15}$ Until the risk of other tumours can be minimised by exclusion of a germline NF2 mutation, these people and their children need continuing screening.

We have now analysed tumour material from nine of these subjects to establish whether mutations present in the tumour are the result of germline or mosaic disease, or are purely somatic events representing chance occurrences in these patients and families. This analysis suggests an approach that may be generally applicable to distinguishing inherited from sporadic tumours in two hit diseases.

\section{Patients and methods}

We studied patients who presented with unilateral vestibular schwannoma but who on further enquiry showed other diagnostic criteria of NF2 or a family history of vestibular schwannoma or meningioma. Between January 1978 and August 1994, a total of 407 patients with unilateral VS were seen at our joint neurosurgery/otology unit. Since 1990, all patients have been assessed by magnetic resonance imaging with gadolinium enhancement, so that any other cranial tumour would almost certainly have been identified. In an earlier study, 93 of the 407 patients were 
Table 1 Subjects with unilateral vestibular schwannomas and other features suggestive of NF2 in a series of 537 cases

\begin{tabular}{|c|c|c|c|c|c|c|}
\hline Case & Sex & $\begin{array}{l}\text { Age at first } \\
\text { symptom }\end{array}$ & $\begin{array}{l}\text { Age at } \\
\text { diagnosis }\end{array}$ & Other NF2 features & Family history & $\begin{array}{l}\text { Conclusion after } \\
\text { DNA studies }\end{array}$ \\
\hline \multicolumn{7}{|c|}{ From 93 retrospective cases (ref 15) } \\
\hline 1 & $\mathbf{F}$ & 33 & 36 & Ulnar neurofibroma & Nil & \\
\hline 2 & $\mathbf{F}$ & 66 & 68 & Nil & Sister (3) VS (UL) & Sporadic \\
\hline 3 & $\mathbf{F}$ & 53 & 69 & Nil & Sister (2) VS (UL) & Sporadic \\
\hline 4 & $\mathbf{F}$ & 15 & 29 & 5 café au lait $>1.5 \mathrm{~cm}$ & Nil & Sporadic or mosaic \\
\hline 5 & $\mathbf{M}$ & 28 & 38 & 2 thoracic schwannomas at age 45 y (IL) & Nil & Sporadic or mosaic \\
\hline \multicolumn{7}{|c|}{ From prospective series $(n=130)$} \\
\hline 6 & $\mathbf{M}$ & 64 & 72 & Nil & Meningioma sister; VS cousin (UL) 62 y & (1) \\
\hline 7 & $\mathrm{~F}$ & 39 & 39 & PLO (CL) $30 y$ & Nil & Sporadic or mosaic \\
\hline 8 & $\mathbf{F}$ & 43 & 46 & 3 meningiomas & Nil & (2) \\
\hline 9 & $\mathbf{M}$ & 48 & 50 & 11 subcutaneous schwannoma spinal tumours on scan, PLO & Nil & Mosaic \\
\hline 10 & $\mathbf{M}$ & 47 & 48 & Facial schwannoma (CL) & Nil & $(2)$ \\
\hline \multicolumn{7}{|c|}{ Other known cases } \\
\hline 11 & $\mathbf{M}$ & 41 & 42 & Schwannoma behind knee & Nil & Sporadic or mosaic \\
\hline 12 & $\mathbf{F}$ & 52 & 56 & Trigeminal tumour (CL) & Meningioma in niece & Sporadic or mosaic \\
\hline 13 & $\mathbf{F}$ & 35 & 50 & 3 meningiomas (IL) & Nil & (2) \\
\hline 14 & $\mathbf{F}$ & 43 & 52 & Recurrent tumour (IL) trigeminal tumour (CL) & Nil & (2) \\
\hline 15 & $\mathbf{F}$ & 41 & 43 & Brain stem glioma & Nil & (2) \\
\hline
\end{tabular}

$\mathrm{UL}=$ unilateral; IL = ipsilateral; CL = contralateral; PLO = posterior subcapsular lenticular opacity (cataract). (1) DNA analyses inconclusive; (2) DNA analyses incomplete because of lack of tissues. Patients $5,8,9$, and 13 fulfil the modified criteria for NF2 detailed in table 3.

selected on geographical but not clinical criteria for more detailed study. ${ }^{15}$ Five of these 93 met our criteria for inclusion in the present study. Between August 1994 and May 1997, a further 130 consecutive referrals have been studied prospectively. A family history of CNS tumours was sought and patients were examined for café au lait patches and cutaneous tumours, and by slit lamp to identify cataracts. Five of these prospective cases met our criteria for inclusion. Thus approximately 4-5\% (10/ 223) of carefully investigated subjects showed features suggestive of NF2. A further five subjects from the clinic database were known to have relevant features, making 15 study subjects in all (table 1), chosen from a total of 537 patients.

\section{SAMPLES}

DNA from tumours (vestibular schwannomas or meningiomas) was extracted, either from formalin fixed paraffin embedded material retrieved from the pathology archives or from frozen tissues as previously described. ${ }^{16}$ Specimens were assessed by a pathologist to identify tumour rich (subjectively $>90 \%$ tumour cells) and normal tissues. Normal and tumour tissues were microdissected from $10 \mu \mathrm{m}$ unstained

Table 2 NF2 mutations in tumour samples

\begin{tabular}{|c|c|c|c|c|}
\hline Case & Tumour mutation & $\begin{array}{l}\text { LOH: } \\
\text { NF2CA3 }\end{array}$ & $\begin{array}{l}\text { LOH: } \\
\text { D22S280 }\end{array}$ & $\begin{array}{l}\text { Germline } \\
\text { mutation }\end{array}$ \\
\hline 2 & 649del(11) & $\mathbf{U}$ & tve & -ve \\
\hline 4 & 653del(G) & tve & ND & -ve \\
\hline 5 & Intron 4 splice acceptor ag $\rightarrow \mathrm{gg}$ & tve & tve & -ve \\
\hline 7 & 1529del(26) & tve & ND & -ve \\
\hline \multirow[t]{2}{*}{9} & $\begin{array}{l}\text { Tumour } 1 \\
\text { R262X Intron } 14 \text { splice donor } 4 \text { bp deletion }\end{array}$ & -ve & -ve & -ve \\
\hline & $\begin{array}{l}\text { Tumour } 2 \\
\text { R262X }\end{array}$ & tve & tve & \\
\hline 11 & Y266X Intron 11 splice donor $\mathrm{gt} \rightarrow \mathrm{at}$ & -ve & ND & -ve \\
\hline 12 & R57X S444X & -ve & ND & -ve \\
\hline 8 & No mutation detected & -ve & -ve & -ve \\
\hline 6 & No mutation detected & ND & ND & $-v e$ \\
\hline 1 & No tumour available & ND & ND & -ve \\
\hline 3 & No tumour available & ND & ND & -ve \\
\hline 13 & Insufficient tumour material & ND & ND & -ve \\
\hline 14 & No tumour available & ND & ND & -ve \\
\hline 10 & No tumour available & ND & ND & ND \\
\hline 15 & No tumour available & ND & ND & ND \\
\hline
\end{tabular}

Loss of heterozygosity results: +ve LOH detected; -ve heterozygosity retained; U: uninformative (blood DNA homozygous); ND: not done. Numbering of nucleotides and amino acids according to ref 8 . serial sections. The encapsulated structure of schwannomas usually allows tumour material to be dissected out with little stromal contamination. Paraffin embedded material was deparaffinised and all tissues were digested overnight with proteinase $\mathrm{K}(200 \mathrm{mg} / \mathrm{l})$ at $55^{\circ} \mathrm{C}$ in a buffer containing $50 \mathrm{mmol} / \mathrm{l}$ Tris- $\mathrm{HCl}(\mathrm{pH}$ $8.0), 0.5 \mathrm{mmol} / \mathrm{l}$ EDTA, and $0.5 \%$ Tween 20 . DNA was then extracted using a conventional phenol-chloroform method. Constitutional DNA of affected subjects was extracted from peripheral blood lymphocytes by standard procedures.

\section{MUTATION ANALYSIS}

All 17 exons of the NF2 gene were screened for mutations by SSCP heteroduplex analysis. ${ }^{17}$ Flanking primers ${ }^{818}$ were used to amplify each exon by PCR in a reaction volume of $20 \mu \mathrm{l}$ containing $125 \mathrm{ng}$ of genomic DNA, $0.5 \mu \mathrm{mol} / 1$ of each primer, $0.75 \mathrm{mmol} / 1$ of each deoxynucleotide triphosphate, 0.5 units of Taq polymerase (Gibco BRL), and reaction buffer (67 $\mathrm{mmol} / \mathrm{l}$ Tris- $\mathrm{HCl}$, pH 8.0, $16.6 \mathrm{mmol} / 1$ $\left(\mathrm{NH}_{4}\right)_{2} \mathrm{SO}_{4}, 6.7 \mathrm{mmol} / 1 \mathrm{MgCl}_{2}$, and $0.17 \mathrm{mg} / \mathrm{ml}$ BSA). The PCR products were denatured, electrophoresed through a $0.7 \times$ HydrolinkMDE gel (AT Biochem) at $250 \mathrm{~V}$ for 13-16 hours, and visualised by silver staining. ${ }^{16} 19$ Samples showing heteroduplex or SSCP variants or both were characterised by cycle sequencing both forward and reverse strands on an ABI 373 sequencer using the Applied Biosystems DyeDeoxy terminator kit.

LOSS OF HETEROZYGOSITY ANALYSIS

Two short tandem repeat polymorphisms (STRPs) from chromosome 22q were used for loss of heterozygosity ( $\mathrm{LOH})$ analyses. NF2CA3 is a CA repeat located within the NF2 gene, with nine alleles and a heterozygosity of $0.83 .^{20} \mathrm{D} 22 \mathrm{~S} 280$ (Afm255xf6) is a CA repeat located $2 \mathrm{cM}$ distal of the NF2 gene, with seven alleles and a heterozygosity of $0.82 .^{21}$ PCR reactions were carried out as described above. PCR products were electrophoresed in an $8 \%$ non-denaturing polyacrylamide gel and visualised by silver staining as above. Allele loss was assessed visually by three 
Table 3 Diagnostic criteria for NF2. NIH criteria are from ref 24 and the additional criteria are from ref 23

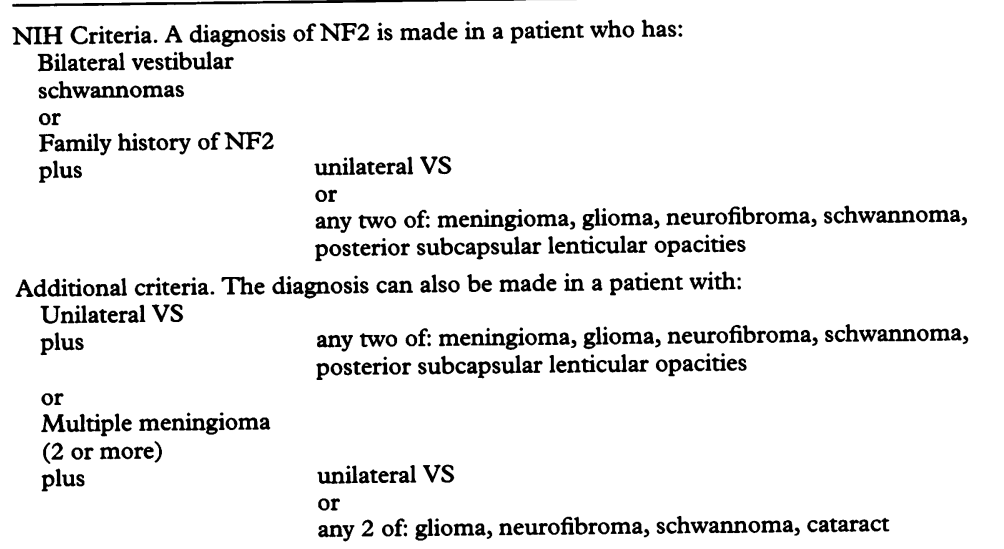

experienced investigators independently, as previously described. ${ }^{22}$ Allele loss was recorded if the intensity of one of the alleles in the tumour sample was significantly reduced relative to the corresponding allele in the normal tissue. The retained allele in the tumour and the corresponding normal allele were used to normalise for differences in amplification or gel loading. Allele loss or retention was scored only if there was complete concordance of the three independent assessments. All samples showing $\mathrm{LOH}$ were subject to repeat analysis after at least two independent PCR amplifications. The low degree of stromal contamination in microdissected schwannomas made this analysis simpler than in many other tumour types, and in all cases replicate tests gave identical results.

\section{Results}

From a total of 537 patients with unilateral vestibular schwannoma, 15 have been identified as having other features of NF2. Clinical details of these patients and their family histories are summarised in table 1 . Four patients had a family history of either a unilateral vestibular schwannoma, a meningioma, or both in a first or second degree relative; two of these four were sisters (patients 2 and 3 ) who were both in the study. Six, including one of the four with an affected relative, had a single further NF2 related tumour (schwannoma, meningioma, glioma, neurofi- broma) and four had a further two or more neurogenic tumours (which meant they fulfil our modified criteria for $\mathrm{NF}^{23}$ ). Finally, one patient had multiple café au lait patches and one had an early onset posterior subcapsular cataract. The mean age at onset of symptoms was 46.5 years. This compares with 47.5 for the series as a whole. All these patients have been followed up with regular clinical and audiological examination and the children (11 in total) of five of the patients have also been assessed. No features of NF2 were found in any of the children.

\section{MOLECULAR ANALYSIS}

Tumours from nine of the 15 cases have been analysed for mutations in the NF2 gene (for one additional patient there was insufficient material to analyse). No tumour material was available from the other five patients (one had died before the study, two were still awaiting surgery, and tissue block material could not be found from two patients). Results of the analysis are shown in table 2. Both "hits" were established in seven of the nine tumours, but two (patients 6 and 8) had no detectable NF2 defect. Tumour and blood DNA was screened in parallel and none of the mutational events in any tumour was found in the patient's blood; indeed no mutations were identified in the blood DNA from any of these patients after analysis of all 17 exons of the NF2 gene. In one patient (9), two tumours were shown to share the same mutation. In the absence of germline mutation, this is strongly suggestive of mosaicism. Blood DNA was also analysed from four (patients 1, 313 , and 14) of the six patients from whom no usable tumour material was available, and again no NF2 mutations were found.

\section{Discussion}

The National Institutes of Health laid out diagnostic criteria for NF2 at a consensus meeting in $1987 .{ }^{24}$ These criteria, summarised in table 3 , mean that any person with bilateral vestibular schwannomas was assumed to have NF2, so that his children were considered to be at $50 \%$ risk. Unilateral vestibular schwannomas are normally sporadic. They are not rare, and so there must be a finite chance that a person will suffer two independent sporadic VS,

Table 4 Implications of molecular analysis

\begin{tabular}{|c|c|c|}
\hline Tumour analysis & Further analysis of patient's DNA & Implication for patient and family \\
\hline \multirow[t]{2}{*}{2 mutations seen, or 1 mutation $+\mathrm{LOH}$} & $\begin{array}{l}\text { Blood +ve } \\
\text { Same mutation in 2nd tumour; blood -ve }\end{array}$ & $\begin{array}{l}\text { NF2 } \\
\text { Mosaic NF2. People related through parents (eg } \\
\text { sibs) are not at risk. Children are at risk; risk can } \\
\text { be excluded if their blood is negative for } \\
\text { mutation(s) seen in parent's tumour. }\end{array}$ \\
\hline & Single tumour; blood -ve & $\begin{array}{l}\text { Risk of mosaic NF2. Children are at risk; risk can } \\
\text { be excluded if their blood is negative for } \\
\text { mutation(s) seen in parent's tumour. }\end{array}$ \\
\hline LOH only & $\begin{array}{l}\text { 2nd tumour also LOH - different allele lost } \\
\text { 2nd tumour also LOH - same allele lost }\end{array}$ & $\begin{array}{l}\text { Sporadic, not NF2 } \\
\text { Risk of NF2. Risk to relatives: } \\
\text { relatives having no allele IBD` are not at risk } \\
\text { relatives sharing the lost allele are not at risk } \\
\text { relatives sharing the retained allele are at risk }\end{array}$ \\
\hline 1 mutation only & $\begin{array}{l}\text { Blood +ve } \\
\text { Same mutation in 2nd tumour; blood -ve } \\
\text { Single tumour, or 2nd tumour with different mutation; blood -ve }\end{array}$ & $\begin{array}{l}\text { NF2 } \\
\text { Mosaic NF2 } \\
\text { Risk of NF2 (mosaic or non-mosaic) }\end{array}$ \\
\hline No mutation or $\mathrm{LOH}$ & & Risk of NF2 (mosaic or non-mosaic) \\
\hline
\end{tabular}

*IBD = identical by descent. 
leading to a wrong diagnosis of NF2. The annual incidence rate for VS is now thought to be around 1 in 80000 (Thomsen, personal communication), a little higher than the rate of 1 per 100000 previously proposed. ${ }^{25}$ Thus, the lifetime risk of a VS is likely to be around 1 per 1000 ( 1 per 2000 for each eighth nerve) and one person per 2 million of the population would be expected to develop bilateral disease as two independent sporadic events. As the birth incidence of NF2 is 1 in $35000,{ }^{26}$ it seems possible that $2 \%$ of patients classified as having NF2 actually may have sporadic bilateral VS. In practice, a diagnosis of NF2 is less likely in older patients, patients with a long interval between two VSs, and patients with a history of exposure to environmental risk factors. However, coincidence is extremely unlikely if subjects develop bilateral VS at young ages or have additional features of NF2. Our present series was made of cases that did not fulfil NIH criteria. There are two groups of patients who do not fulfil these criteria but where the possibility of NF2 seems real: patients with several NF2 features (multiple neurogenic tumours or one neurogenic tumour plus other NF2 associated symptoms), and patients with a family history of isolated neurogenic tumours. We suggested ${ }^{23}$ additional criteria for NF2 which are listed in table 3. We recently showed that in six of 17 cases that fulfilled these modified NF2 criteria (presenting at other clinics and not included in the present series) a germline mutation could be found. This detection rate is comparable to that seen for classical NF2, ${ }^{11}{ }^{12}$ suggesting that the modified criteria are valid. However, in the present series, although four patients $(13,5,8$, and 9) fulfilled the modified criteria, no germline mutations have been found and in two of these (patients 5 and 9) germline mutations have been excluded by showing both hits in the tumour, neither of which was present in blood. These results do not invalidate the modified criteria. At least one of these patients (patient 9) is almost certainly mosaic. Additionally, we have recently shown that many cases of classical NF2 are also mosaic. ${ }^{6}$ Subjects fulfilling these modified criteria will mostly be at risk of further tumours and many will be at risk of transmitting a mutated NF2 gene to their children.

Sporadic unilateral VS will sometimes appear to be familial. The average person in the UK is likely to have five first degree and 10 second degree relatives, so that our series of 537 patients with unilateral VS would have around 2685 first degree and 5000 second degree relatives. Given the lifetime risk of 1 in 1000 of VS, two to three cases of sporadic vestibular schwannoma would be expected to occur in the first degree relatives of our series. In the event, only one pair of affected first degree relatives has been identified (two sisters, patients 2 and 3). Our molecular studies have shown that their tumours are unrelated and thus a chance association. Patient 2 shows two hits in the tumour, neither of which is present in her blood, while no germline mutation could be detected in her sister (patient 3); tumour from patient 3 was not available. It is likely that the majority of cases of isolated vestibular schwannoma occurring in close relatives are entirely coincidental.

In this study we have shown that the majority of patients presenting with histories suggestive of NF2, but in whom classical criteria are not met, do not have germline mutations in the NF2 gene. We were also able to exclude germline NF2 mutations in a patient (4) with the association of five café au lait patches with an early onset VS, and a patient (7) with cataract with a unilateral tumour. The same is likely to be true for many instances of a single NF2 related tumour occurring in association with a unilateral vestibular schwannoma. However, some patients may be somatic mosaics, particularly those with another definitive feature of NF2 in addition to their VS. In true mosaic cases, both tumours would contain a mutation in common. The spectrum of mutations found in the tumours was similar to other series of unilateral vestibular schwannoma. ${ }^{27}$ In those cases that are mosaic it may be possible to make tentative assumptions about disease severity in offspring based on the type of mutation. ${ }^{13}{ }^{14}$ It might be expected that the two splice site mutations, if mosaic in the gonads, would be associated with milder disease in any affected offspring.

Comparing constitutional and tumour DNA, including comparisons in multiple tumours or multiple affected relatives, offers a useful approach to excluding germline mutations. In many tumour prone disorders such as NF1, familial adenomatous polyposis, retinoblastoma, and von Hippel-Lindau disease, patients may be subjected to continuing screening and worry even though no mutation was detected on analysis of their blood DNA. This is because it is not possible to identify mutations in all classically affected subjects, and therefore failure to detect a mutation does not exclude the diagnosis. This is particularly the case for children or sibs of patients with unilateral retinoblastoma. Although the risk of a sib being affected is only $1-2 \%,{ }^{28}$ it is still routine practice to screen these children in the same way as those at $50 \%$ risk. This can entail repeated general anaesthetics with the associated trauma to the child, worry for the parents, and costs for the Health Service. As table 4 shows, identification of both mutations (or one mutation plus loss of heterozygosity) in the tumour and exclusion of these in the germline of the affected case and their sibs or offspring should be sufficient to obviate the need for screening.

This approach has been used for our own series of patients with features suggestive of NF2, with a potential saving of unnecessary anxiety for patients and their family and of the costs of clinicians' time, audiological tests, and MRI scans. The same analysis could be used for patients presenting with a single VS at an unusually early age. One possible caveat concerns the analysis of multifocal tumours. Patients with NF2 have a tendency to develop multifocal tumours ${ }^{29}$ where more than one clonal population may exist. In theory, two 
separate mutations might be identified in a tumour specimen, both of which represent the second hit in different clonal populations within the tumour, and meanwhile a germline mutation could exist undetected. To avoid the risk of such mistakes, the neuro-otological team specifically note the presence of multifocal tumours, and during microdissection the blocks are checked for appearances suggestive of separate tumours. No evidence of such problems was seen in our series.

So far, three subjects (patients 7, 12, and 4) have been informed of their molecular findings and reassured that they do not have NF2, although they may have a small patch of cells affected and the small chance of developing further tumours has been explained. Audiological and clinical screening has been discontinued. Mutation testing has been offered to five children from these families. Exclusion of the mutation or mutations found in the tumour will reduce their risk of NF2 to population levels.

We thank Dr Helen Reid for helping to locate samples for molecular analysis. This work was supported by a grant from the North West Regional Health Authority.

1 Kanter WR, Eldridge R, Fabricant R, Allen JC, Koerber T. Central neurofibromatosis with bilateral acoustic neuroma. Genetic, clinical and biochemical distinctions from peripheral neurofibromatosis. Neurology 1980;301:851-9.

2 Evans DGR, Huson SM, Donnai D, et al. A clinical study of type 2 neurofibromatosis. $Q \mathcal{F}$ Med 1992;84:603-18.

3 Parry DM, Eldridge R, Kaiser-Kupfer MI, Bouzas EA, Parry DM, Eldridge R, Kaiser-Kupfer MI, Bouzas EA,
Pikus A, Patronas N. Neurofibromatosis 2 (NF2): clinical Pikus A, Patronas N. Neurofibromatosis 2 (NF2): clinical
characteristics of 63 affected individuals and clinical evidence for heterogeneity. Am $\mathcal{F}$ Med Genet 1994;52:450-

4 Evans DGR, Ramsden R, Huson SM, et al. Type 2 neurofibromatosis: the need for supraregional care. $\mathcal{F}$ Laryngol Otol 1993;107:401-6.

5 Knudson AG. Mutation and cancer: statistical study of retinoblastoma. Proc Natl Acad Sci USA 1971;68:820.

6 Evans DGR, Trueman L, Wallace A, Wu CL, Strachan T Mosaicism in classical NF2: a common mechanism fo sporadic disease in tumour prone syndromes? Am $7 \mathrm{Hum}$ Genet (in press)

7 Wertelecki W, Rouleau GA, Superneau DW, et al. Neurofibromatosis 2: clinical and DNA linkage studies of a large kindred. $N$ Engl f Med 1988;319:78-83.

8 Rouleau GA, Merel P, Lutchman M, et al. Alteration in a new gene encoding a putative membrane-organizing protein causes neuro-fibromatosis type 2 . Nature 1993;363: protein caus

9 Troffater JA, MacCollin M, Rutter JL, et al. A novel moesin-, ezrin-, radixin-like gene is a candidate for the neurofibromatosis 2 tumor suppressor. Cell 1993;72:791800 .
10 MacCollin M, Ramesh V, Jacoby LB, et al. Mutational analysis of patients with neurofibromatosis $2 . \mathrm{Am} \mathrm{f} \mathrm{Hum}$ Genet 1994;55:314-20.

11 Bourn D, Carter SA, Mason S, Evans DGR, Strachan T. Germline mutations in the neurofibromatosis type 2 tumour suppressor gene. Hum Mol Genet 1994;5:813-16.

12 Merel P, Hoang-Xuan K, Sansom M, et al. Screening for germline mutations in the NF2 gene. Genes Chrom Cancer 1995;12:117-27.

13 Parry DM, MacCollin M, Kaiser-Kupfer MI, et al. Germ-line mutations in the neurofibromatosis 2 gene: correlations with disease severity and retinal abnormalities. Am $\mathcal{F}$ Hum Genet 1996;59:529-39.

14 Ruttledge MH, Andermann AA, Phelan CM, et al. Type of mutation in the neurofibromatosis type 2 gene (NF2) frequently determines severity of disease. Am $\mathcal{F}$ Hum Gene 1996;59:331-42.

15 Neary W, Newton VE, Laiode-Kemp SN, et al. A clinical, genetic and audiological study of patients with type 2 neugenetic and audiological study of patients with type 2 neurofibromatosis. I. Clinical features of neurofibromatosis in patients with unilateral

16 Wu CL, Sloan P, Read AP, Harris R, Thakker NS. Deletion mapping on the short arm of chromosome 3 in squamous cell carcinoma of the oral cavity. Cancer Res 1994;54:6484 8.

17 Orita M, Iwahana H, Kanazawa H, Hayashi K, Sekiya T. Detection of polymorphisms of human DNA by gel electrophoresis as single-strand conformation polymorphisms. Proc Natl Acad Sci USA 1989;86:2766-70.

18 Jacoby LB, MacCollin M, Louis DN, et al. Exon scanning for mutation of the NF2 gene in schwannomas. Hum Mol Genet 1994;3:413-19.

19 Lenke U, Hanke R, Kraft U, Grade I, Grunewald I, Speer A. Non-isotopic analysis of single strand conformation polymorphism (SSCP) in the exon 13 region of the human dystrophin gene. $\mathcal{F}$ Med Genet 1993;30:951-4.

20 Bourn D, Strachan T. Highly polymorphic dinucleotide repeat at the NF2 locus. Hum Genet 1995;95:712.

21 Gyapay G, Morisette J, Vignal A, et al. The 1993-4 Généthon human genetic linkage map. Nat Genet 1994;7: 246-339.

22 Trapman J, Sleddens HFBM, van der Weiden MM, et al. Loss of heterozygosity of chromosome 8 microsatellite loci implicated a candidate tumour suppressor gene between the loci D8S87 and D8S133 in human prostate cancer. Cancer Res 1994;54:6061-4.

23 Evans DGR, Huson SM, Donnai D, et al. A genetic study of type 2 neurofibromatosis. II. Guidelines for genetic counselling. F Med Genet 1992;29:847-52.

24 National Institutes of Health Consensus Development Conference Statement on Neurofibromatosis. Neurofibromatosis Res Newsl 1987;3:3-6.

25 Tos M, Thomsen J. Epidemiology of acoustic neuromas. $f$ Laryngol Otol 1984;98:685-92.

26 Evans DGR, Huson SM, Donnai D, et al. A genetic study of type 2 neurofibromatosis in the north west of England and the UK. I. Prevalence, mutation rate, fitness, and confirmation of maternal transmission effect on severity. $\mathcal{F}$ Med Genet 1992;29:841-6.

27 Irving RM, Moffat DA, Hardy DG, Barton DE, Xuereb JH Maher ER. Somatic gene mutations in familial and non-familial vestibular schwannoma. Hum Mol Genet 1994;3:347-50.

28 Draper GJ, Sanders BM, Brownbill PA, Hawkins MM. Patterns of risk of hereditary retinoblastoma and applications terns of risk of hereditary retinoblastoma and applicat

29 Martuza RL, Ojemann RG. Bilateral acoustic neuromas: clinical aspects, pathogenesis and treatment. Neurosurgery 1982;10:1-12. 